\title{
Research and Development of Trace Sample Device Control System
}

\author{
Lin $\mathrm{Na}^{\mathrm{a}}$, Zhang Lijian ${ }^{\mathrm{b}}$ \\ Binzhou Polytechnic, Binzhou, Shandong 256600 \\ axianruibrother@163.com, b316597309@qq.com
}

\begin{abstract}
At present it is difficult for the tradition metric equipment to adapt the modernization mass production, a new trace sample device, implements trace liquid automatic adjustment, real-time monitoring and accurate adjustment, using PLC technology and touch screen technology, servo motor technology as the core. Device is expounded in detail the mechanical structure, hardware composition, software, and experimental verification. The sample device has simple structure and is maintenance-friendly with touch screen operation and friendly man-machine interface. It can be widely applied in the fields such as medicine, chemical, etc., where the liquid should be added precisely.
\end{abstract}

Keywords: Mechanical structure, Touch screen, Sample device, Real time monitoring

\section{Introduction}

Along with development of biochemical and medical technology, the number of samples used in medical testing, chemical testing, commercial testing, etc., is constantly increasing. Manual sample adding is far from enough to satisfy the demand of today's technicians. When the samples are distributed and transferred by hand, serious problems occur, such as low working efficiency, easily contaminated laboratory equipment and infected operators, poor sampling accuracy, large operation error, etc. Thus, a sample device that can realize fully automatic operation is called for in the market. This paper designs a fully automatic sample device based on PLC and touch screen. It has powerful man-machine interface, is easy to operation and can be widely applied in lab fields where the samples should be added precisely.

\section{The system overall design}

The overall structure is shown in figure 1,Mainly by the $\mathrm{X}$ axis transmission mechanism, $\mathrm{Y}$ axis transmission mechanism, the $\mathrm{Z}$ axis transmission mechanism, control system and human-machine interface and other components (See Fig.1).

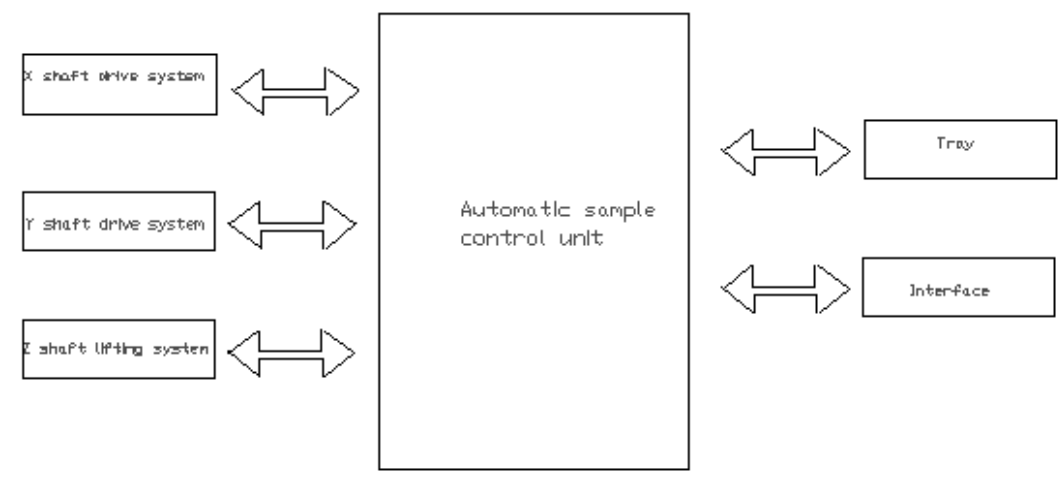

Fig. 1 The system overall structure 
Several test tubes are placed on tray in matrix way, $\mathrm{X}$ axis transmission mechanism, the $\mathrm{Y}$ axis transmission mechanism, the $\mathrm{Z}$ axis transmission mechanism is controlled by the control system positioning to specify the top of the sample tube precisely, then sample device is open, the system test tube sample according to the capacity.

\section{Mechanical structure}

The sample device includes a base, an $\mathrm{X}$-axis transmission mechanism, a $\mathrm{Y}$-axis transmission mechanism, a $Z$-axis transmission mechanism and a sample device. (See Fig.2)

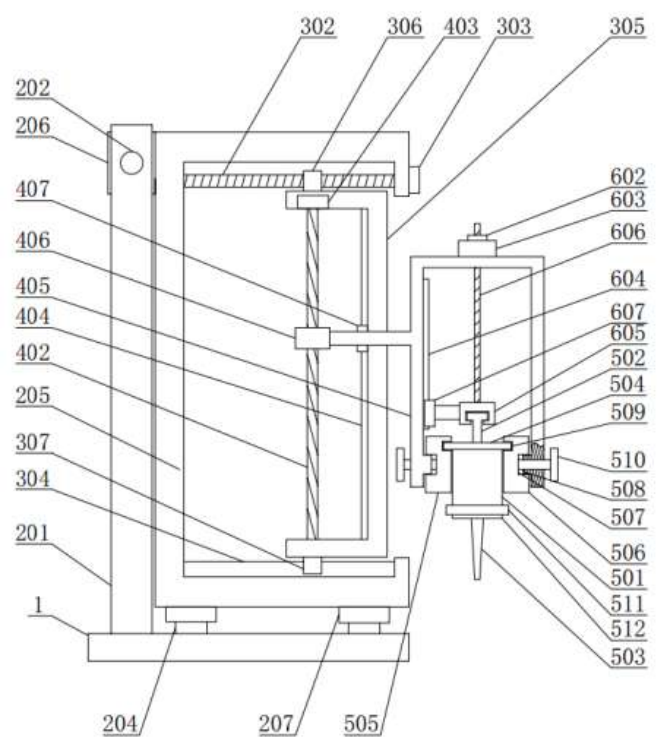

Fig. 2 Mechanical design of the sample device

The $\mathrm{X}$-axis transmission mechanism includes $\mathrm{X}$-axis support frame, $\mathrm{X}$-axis screw, $\mathrm{X}$-axis motor, $\mathrm{X}$-axis slide rail and $\mathrm{Y}$-axis support frame. The $\mathrm{X}$-axis support frame is installed on the base. The $\mathrm{X}$-axis screw is installed on the upper end of $\mathrm{X}$-axis support frame and rotatably connected with the $\mathrm{X}$-axis support frame. $\mathrm{X}$-axis motor is situated on the $\mathrm{X}$-axis support frame and connected with $\mathrm{X}$-axis screw in a gearing manner. $\mathrm{X}$-axis slide rail is placed on the base and parallel to the $\mathrm{X}$-axis screw. An $\mathrm{X}$-axis screw nut which corresponds to $\mathrm{X}$-axis screw is placed on the upper end of $\mathrm{Y}$-axis support frame and the lower end of $\mathrm{Y}$-axis support frame is equipped with $\mathrm{X}$-axis slide block that corresponds to the $\mathrm{X}$-axis slide rail.

Y-axis transmission mechanism includes $\mathrm{Y}$-axis crew, $\mathrm{Y}$-axis motor, $\mathrm{Y}$-axis slide rail and $\mathrm{Z}$-axis support frame. The Y-axis screw is installed on the upper end of Y-axis support frame and rotatably connected with the Y-axis support frame. Y-axis motor is situated on the Y-axis support frame and connected with Y-axis screw in a gearing manner. Y-axis slide rail is placed on the lower end of Y-axis support frame and parallel to the Y-axis screw. A Y-axis screw nut which corresponds to $Y$-axis screw is placed on the upper end of $Z$-axis support frame and the lower end of $Z$-axis support frame is equipped with Y-axis slide block that corresponds to the Y-axis slide rail.

Z-axis transmission mechanism includes Z-axis crew, Z-axis motor, Z-axis slide rail and a pipette support frame. The $Z$-axis screw is vertically installed on $Z$-axis support frame and rotatably connected with the $Z$-axis support frame. $Z$-axis motor is situated on the $Z$-axis support frame and connected with $Z$-axis screw in a gearing manner. Z-axis slide rail is vertically placed on the Z-axis support frame and parallel to the Z-axis screw. The pipette support frame is equipped with a Z-axis screw nut which corresponds to $Z$-axis screw and also equipped with Z-axis slide block that corresponds to the Z-axis slide rail.

The sample device includes the pipette, pipette fixture and pipette transmission mechanism. The 
pipette includes the pipette body, the piston rod that fits in the pipette body, and the pick-up tube which is detachably connected with the pipette body. There is an extension plate on the top edge of the pipette body. The pipette fixture includes the firstclamp plate and the second clamp plate which correspond to the pipette body. On the first and second clamp plates, a locating slideway is situated. The pipette support frame is equipped with the locating bump that fits in the locating slideway. Through the locating bump and the locating slideway, the first and the second clamp plates are successfully flexibly connected with the pipette support frame. There are notches respectively on the first and the second clamp plates, which correspond to the extension plate.

The pipette transmission mechanism includes the pipette screw nut, the pipette motor, the pipette slide rail, and the fixed block for fixing the piston rod. The pipette screw nut is installed on the upper end of the pipette support frame and rotatably connected with the pipette support frame. In the nut, there is a vertical pipette screw that corresponds to the nut. The pipette motor is installed on pipette support frame and rotatably connected with the pipette screw nut. The pipette slide rail is vertically installed on the pipette support frame and parallel to the pipette screw. On the fixed block for piston rod, there is a pipette slide block that fits in the pipette slide rail. The fixed block is also connected the pipette screw.

\section{System control}

System control structure

PLC is responsible for the various tasks in the system in coordination, driven by servo motor for motion control. It adopts touch screen as the monitoring interface, realizing the human-computer interaction function. (See Fig.3)

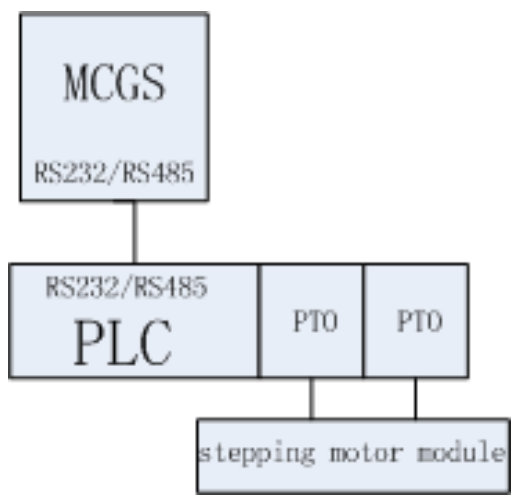

Fig.3: System control structure

\section{Hardware}

\section{PLC selection}

In the control system, PLC is responsible to control the motion of relay and servo motor, such as signal collection, logical operations, signal output. According to the number of input and output nodes and control requirements, Huichuan H2U-3232MTQ series PLC is elected, which has the procedure capacity of $24 \mathrm{k}$ and is equipped with program encrypting function. It is also self-equipped with 32 digital input points, 32 digital output points, and provides multichannel input and output ports of high frequency and high speed, with powerful motion and location control function.

\section{Servo driver}

Huichuan IS580 drivers are selected as X -axis transmission mechanism, Y-axis transmission mechanism and Z-axis transmission mechanism. They have two control systems of closed circuit 
vector control and $\mathrm{V} /$, with the torque control precision of $\pm 5 \%$ and the steady speed precision of $\pm 0.02 \%$.

\section{Servo motor}

In order to ensure a reliable and practical system operation, the step motor is required to have higher precision. Thus, SYNTRON 35BYG250BK two-phase hybrid step motor is selected, which has static phase current of $0.8 \mathrm{~A}$, holding torque of $0.11 \mathrm{Nm}$, positioning torque of $0.012 \mathrm{Nm}$ and rotational inertia of $14 \mathrm{gcm} 2$. The step driver has a model number of SD-20403, and 16 sub-modes and 8 types of output currency are available for choice.

Touch screen

MCGS( Monitor and Control Generated System) is adopted to provide the users with a complete set of programs and operational tools which are used to solve the actual engineering problems, such as device driving, data acquisition, data processing, alarm processing, process control, animation display, report output, etc.

TPC7062TX is a set of embedded and integrated touch screen which has high performance and takes the advanced Cortex-A8 CPU as the core (basic frequency: 600MHz). The product adopts 7 -inch high-luminance TFT LCD screen(the resolution is $800 \times 480$ ) and four-wire resistive touch screen(the resolution is $4096 \times 4096$ ). It has powerful image display and data processing function.

\section{Software design}

\section{PLC software design}

The sequential control design method of PLC is adopted. Firstly, the state flow chart is developed, and step ladder instruction is used to prepare the control program. Relevant calculation formulas are written in the PC scripts, including main program, flushing, testing, temperature control and other sub- programs. See the followings for temperature PID control program codes:

$\begin{array}{llll}\text { LD } & \text { M8000 } & \text { LD } & \text { M8000 } \\ \text { FROM } & \text { K0 K7 D50 K1 } & \text { ANI } & \text { M39 } \\ \text { LD } & \text { M8000 } & \text { TOP } & \text { K4 K0 H1111 K1 } \\ \text { DESUB } & \text { K200 K0 D20 } & \text { TO } & \text { K4 K1 D66 K1 } \\ \text { DESUB } & \text { K1000 K0 D22 } & \text { LD } & \text { M8000 } \\ \text { DEDIV } & \text { D20 D22 D24 } & \text { AND } & \text { M39 } \\ \text { DEMUL } & \text { D24 D50 D48 } & \text { PID } & \text { D226 D62 D300 D68 } \\ \text { INT } & \text { D48 D62 } & \text { LD } & \text { M8000 } \\ \text { LD } & \text { M8000 } & \text { AND } & \text { M39 } \\ \text { ANI } & \text { M39 } & \text { DESUB } & \text { K1000 K0 D40 } \\ \text { PID } & \text { D226 D62 D200 D64 } & \text { DESUB } & \text { K32767 K0 D42 } \\ \text { LD } & \text { M8000 } & \text { DEDIV } & \text { D40 D42 D44 } \\ \text { ANI } & \text { M39 } & \text { DEMUL } & \text { D44 D68 D28 } \\ \text { DESUB } & \text { K1000 K0 D30 } & \text { INT } & \text { D28 D70 } \\ \text { DESUB } & \text { K32767 K0 D32 } & \text { LD } & \text { M8000 } \\ \text { DEDIV } & \text { D30 D32 D34 } & \text { AND } & \text { M39 } \\ \text { DEMUL } & \text { D34 D64 D38 } & \text { TOP } & \text { K4 K0 H1111 K1 } \\ \text { INT } & \text { D38 D66 } & & \\ \text { design } & & & \end{array}$

The main interface of the software includes all functions to be realized. The top left corner is for tasks setting, where you can set the functions required, including... The top right corner is for tasks execution and the underneath are respectively parameter setting, functional test, calibration experiment, temperature control curve, system wash, liquid emptying, running records, help, fault query and Exit button.

The parameter setting interface is designed to set the running frequency, running position and database for $\mathrm{X}$ - axis, $\mathrm{Y}$ axis and $\mathrm{Z}$ axis. Relevant configuration can be completed by directly inputting the figures or pulling the scroll bar; The communication settings for touch screen and PLC 
include baud rate for serial ports, data bits, port No., etc.

The functional testing interface can be used to test whether each unit works normally before officially sample adding, such as controlling fore-and-aft movements of $\mathrm{X}$ axis and $\mathrm{Y}$ axis, checking status of keys, indicators, servo motors and sensors.

The calibration experiment interface calibrates the instrument with microbalance. In calibrating, input the volume of liquid added and the required calibration coefficient. The calibration coefficient can guarantee the adding precision of the sample adding system.

As for system wash interface, use the liquid which has been filled with and is pending for adding in the pipe, before carrying out diluting, dispensing, titrating, etc., so as to improve the adding precision. When emptying out the remaining liquid, click the liquid discharging button to discharge the liquid in the medicine bottle and prepare for sample adding and flushing next time.

The running records interface logs the running time of the instrument, faults and codes, user level and other relevant running information.

Help interface does not only introduce the operations and interfaces of PC monitoring system, but describes the maintenance, fault diagnosis and common troubles of the instrument and troubleshooting methods. (See Fig.4)

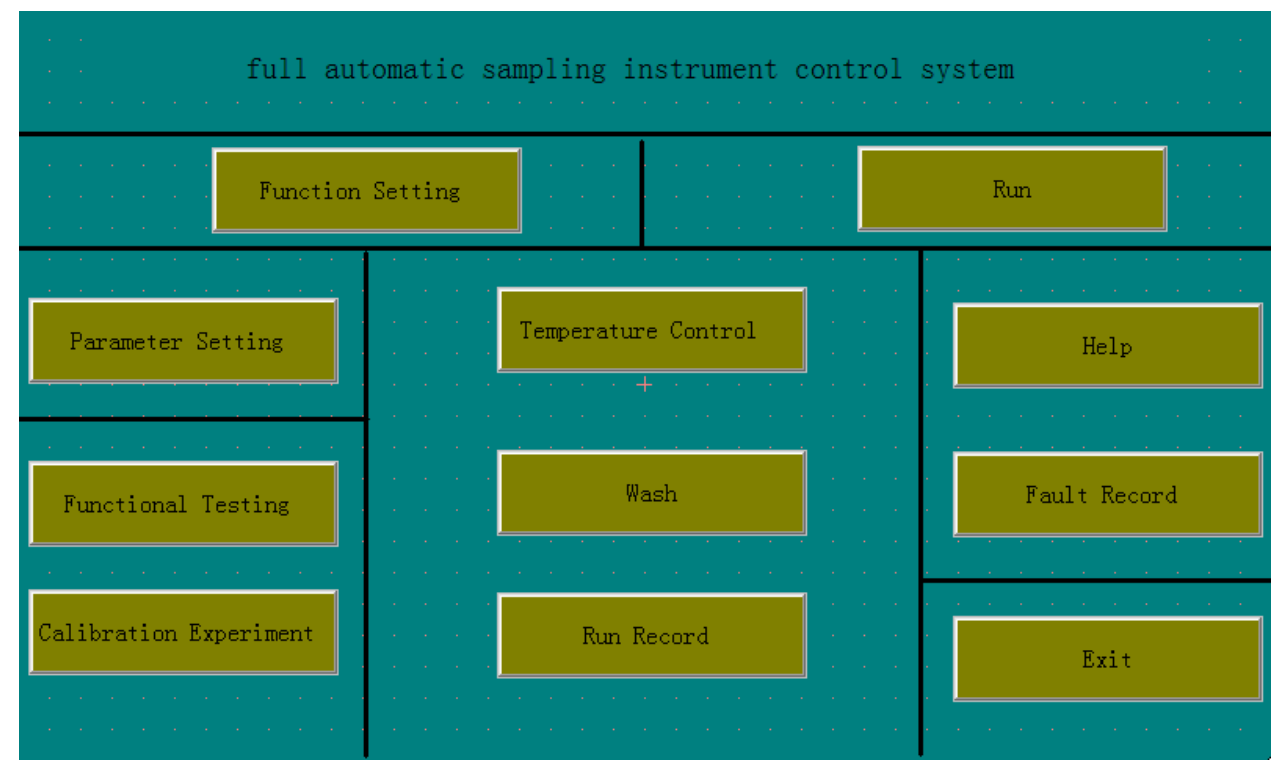

Fig. 4 Master interface of Trace sample device control system

\section{Experiments}

It's very difficult to directly measure the volume of liquid to be added. Thus, the weighing method is used to measure the liquid adding precision. See the followings for measuring method:

1) Place the sample device, electronic balance, etc., in the laboratory with constant temperature and constant humidity, and wait for $1-2$ hours before measuring.

2) Set the electronic balance to zero after placing the small weighing cup on the balance.

3) Put the weighing cup in an appropriate location, add the distilled water with expected volume to the cup through the sample device, and then weigh the cup on the balance.

4) Repeat weighing each type of the added liquid for 10 times. The density of the distilled water below $22^{\circ} \mathrm{C}$ is 0.9968 . Calculate the sample adding error.

The sample device has a wide range of added samples. It's unnecessary to measure and test each sample point. The precision of sample device can be determined only if the reasonable distribution point is selected within the sample ranges. Thus, $5 \mu \mathrm{l}, 10 \mu \mathrm{l}, 20 \mu \mathrm{l}, 30 \mu \mathrm{l}$ and $40 \mu \mathrm{l}$ are 
selected for measuring. In addition, as the experimental environment has constant temperature and humidity, it's unnecessary to convert the weight of the distilled water into the volume. (See Table 1)

Table 1 Precision test data table of the sample device

\begin{tabular}{|l|l|l|l|l|l|}
\hline & $5 \mu \mathrm{l}$ & $10 \mu \mathrm{l}$ & $20 \mu \mathrm{l}$ & $30 \mu \mathrm{l}$ & $40 \mu \mathrm{l}$ \\
\hline \multirow{4}{*}{$v_{\mathrm{i}}$} & 5.11 & 10.22 & 20.11 & 29.97 & 39.98 \\
\cline { 2 - 6 } & 4.99 & 10.11 & 20.21 & 30.21 & 40.19 \\
\cline { 2 - 6 } & 4.99 & 10.14 & 19.98 & 30.00 & 40.12 \\
\cline { 2 - 6 } & 5.11 & 9.91 & 20.14 & 30.11 & 39.99 \\
\cline { 2 - 6 } $\bar{\nu}$ & 5.12 & 10.23 & 20.15 & 30.21 & 40.12 \\
\hline$\sigma$ & 5.064 & 10.12 & 20.12 & 30.10 & 40.08 \\
\hline $\mathrm{S}$ & 0.068 & 0.12 & 0.08 & 0.11 & 0.09 \\
\hline $\mathrm{CV}$ & 0.01 & 0.012 & 0.006 & 0.003 & 0.002 \\
\hline
\end{tabular}

\section{Conclusion}

Actual operation shows that when the distilled water is used as the sample liquid, the accuracy of the automatic sample device can be controlled within $3 \%$ and the precision can be controlled within $1 \%$. This can fully meet the liquid sample mixing demands at different levels.

\section{Reference}

[1] YANG Kun, KOU Zhi-wei, LI Yang and CHENG Jie, "Water Level Control System Design for Solar Water Heating Engineering Based on PLC and Touch Screen ",Computer Knowledge and Technology, vol. 12, no.11, (2016), pp. 264-266.

[2] Zhao Yuan, "Design of an Intelligent Water Supply Control System Based on Mitsubishi FX2N Series PLC", The New Energy Power Control Technology, vol. 38, no.3, (2016), pp. 38-40.

[3] Du Xinjie and Zhu Lianqing, "Fuzzy PID for adding sample arm movement control of ELISA processor", journal of electronic measurement and instrumentation, vol. 28, no.3, (2014), pp. 327-333

[4] DAI Lili and GE Chaolun, "Preliminary Study on Mathematical Model of Liquid Volume Added of TCM Medicinal Broth Decoction Machine”, China Pharmacy, vol. 27, no.1, (2016), pp. $18-22$

[5] SUN Songli,WANG Rong lin,ZHANG Gui xin," Design of PLC Simulation Training System Based on MCGS",research and exploration in laboratory, vol. 34, no.1, (2015), pp. 87-91 